\title{
PROSES FONOLOGIS DAN PENGKAIDAHANNYA DALAM KAJIAN FONOLOGI GENERATIF
}

\author{
Saidatun Nafisah \\ Pendidikan Bahasa Inggris, Fakultas Bahasa dan Seni \\ Universitas Indraprasta PGRI \\ Jl. Nangka No. 58C Tanjung Barat, Jakarta Selatan, Indonesia
}

\begin{abstract}
Abstrak
Tujuan penelitian ini adalah untuk mengetahui proses-proses fonologis beberapa bahasa. Penelitian ini menggunakan metode deskriptif kualitatif dengan pendekatan fonologi generatif. Data penelitian ini adalah data fonologis yang berasal dari beberapa bahasa. Data penelitian ini diambil dengan menggunakan metode refleksif introspektif untuk data bahasa yang dikuasai oleh penulis. Selain bahasa yang dikuasai penulis, data diambil dari buku-buku yang memuat data yang berasal dari bahasa lain. Ada beberapa cara menganalisis data. Yang pertama, mengumpulkan data dan mengidentifikasinya. Yang kedua adalah mengklasifikasikan data, menganalisis data, membuat kaidah fonologis, dan menjelaskan hasil temuan. Dari hasil analisis yang diperoleh, dapat disimpulkan bahwa fonologi generatif dapat menjadi pendekatan yang relevan yang dapat digunakan untuk menjelaskan proses fonologis bahasa-bahasa yang berbeda. Dengan menggunakan fonologi generatif, ditemukan beberapa proses fonologis bahasa antara lain penambahan bunyi, pelesapan bunyi, koalisi, dan asimilasi.
\end{abstract}

Kata Kunci: proses fonologis, kaidah fonologi, fonologi generative

\begin{abstract}
The goal of the research is to describe the phonological processes of some languages. This research uses qualitative descriptive method. The approach of this research is generative phonology. The research data are some words taken from different languages. They are collected using reflective-introspective method and are taken from some books. There are some steps in analyzing the data based on the principles of generative phonology. The first step is collecting and identifying data, followed by classifying data, analysing data, formulating phonological rules, and describing the findings. From the results, it can be concluded that the generative phonology could become a relevant approach for analysing and explaining phonological processes in any languages. The phonological processes include addition of sound, deletion of sound, coalition, and assimilation.
\end{abstract}

Keywords: Phonological Process, Phonological Rules, Generative Phonology

\section{PENDAHULUAN}

Bahasa merupakan sistem bunyi. Ilmu tentang bunyi pada umumnya disebut fonologi. Fonologi mencakup bunyi bahasa, baik yang bersangkutan pembentukan bunyi, bunyi sebagai getaran udara, dan bunyi yang terdengar (ketiganya dikaji oleh fonetik) maupun yang bersangkutan dengan fungsi bunyi dalam komunikasi.

Fonologi generatif merupakan perkembangan fonologi yang digagas oleh Chomsky dan Halle pada 1968. Fonologi Generatif pada umumnya membicarakan proses fonologis suatu bahasa. Oleh karenanya, dalam kajian fonologi generatif dijumpai kaidahkaidah perubahan bunyi. 
Dalam tulisan ini akan dibahas proses fonologis beberapa bahasa yang berbeda. Dari data yang dipaparkan, penulis menganalisis perubahan bunyi pada beberapa bahasa dan menjelaskannya dengan menggunakan kaidah-kaidah fonologi generatif. Proses fonologis yang dibahas dalam tulisan ini meliputi: penambahan segmen, pelesapan segmen, penyatuan segmen (koalisi), dan asimilasi.

\section{KAJIAN TEORI Fonologi Generatif}

Pada 1957, Noam Chomsky mengemukakan gagasan baru dalam ilmu bahasa, yaitu teori generatif. Pada awalnya, teori generatif ini mengkaji bahasa pada tataran tata bahasa. Pada perkembangannya, teori ini dapat diaplikasikan pada tataran fonologis yang kemudian disebut fonologi generatif. Fonologi generatif ini pertama kali muncul di Amerika dan Morris Halle adalah orang pertama yang menerapkan prinsip-prinsip generatif dalam bidang fonologi (Yusuf, 1998: 92). Berdasarkan teori generatif, yang dibahas dalam fonologi generatif antara lain, sistem aturan yang berhubungan dengan suara dan makna, representasi fonetik suatu bahasa, proses terjadinya perubahan bunyi, dan asumsi yang mendasari perubahan bunyi.

Dari paparan di atas dapat diungkapkan bahwa fonologi generatif adalah komponen yang bersumber dari tata bahasa generatif yang diterapkan pada bidang fonologi. Proses fonologis suatu atau perubahan bunyi suatu bahasa menjadi perhatian fonologi generatif. Fonologi generatif menjelaskan proses perubahan bunyi tersebut terjadi.

\section{Fitur Distingtif}

Schane (1992) menyatakan bahwa fonem bukan merupakan satuan yang paling kecil. Ada unit yang lebih kecil yang disebut fitur distingtif atau ciri-ciri pembeda bunyi.

Ciri-ciri pembeda sebuah segmen dalam fonologi generatif didasarkan atas (1) fitur kelas utama (silabis, sonoran, konsonantal); (2) daerah artikulasi (anterior, koronal); (3) cara artikulasi (kontinuan, penglepasan tertunda, striden, nasal, lateral); (4) batang lidah (tinggi, rendah, belakang); (5) bentuk bibir (bulat); (6) tambahan (tegang, bersuara, aspirasi, glotalisasi); dan (7) prosodi (tekanan dan panjang) (Kenstowicz, 1994:452; Schane, 1992a:28-35; dan Carr, 1994 dalam Sawirman).

Sementara itu Dardjowidjojo (2010: 44) menjelaskan bahwa fitur-fitur distingtif yang ada pada konsonan adalah vokalik dan konsonantal, anterior, koronal, kontinuan (malar), straiden, nasal, dan vois (suara). Selanjutnya untuk bunyi vokal, fitur-fitur distingtifnya adalah: tinggi, vokalik (silabis), belakang, bundar, dan tegang.

Dari pemaparan diatas dapat diungkap bahwa ada satuan yang lebih kecil dari fonem, dan satuan terkecil tersebut dijelaskan melalui fitur distingtif. Fitur distingtif ini berfungsi untuk mengetahui unit terkecil dalam analisis bunyi.

\section{Kaidah Fonologi Generatif}

Kaidah-kaidah perubahan bunyi dalam fonologi generatif, antara lain: kaidah perubahan ciri, kaidah pelesapan segmen, kaidah penambahan/penyisipan segmen, kaidah penyatuan segmen (koalisi), dan kaidah metatesis (permutasi). Kaidah-kaidah tersebut diduga berlaku secara universal pada semua bahasa.

Secara umum, kaidah-kaidah tersebut mempunyai rumus seperti di bawah ini: 
1. Penambahan Segmen

Penambahan segmen adalah penambahan atau penyisipan segmen pada kata. Kaidah ini dapat dirumuskan seperti dibawah ini:

$\mathrm{A} \rightarrow \varnothing / \mathrm{B} \_\mathrm{C}$

2. Pelesapan Segmen

Pelesapan segmen adalah penghilangan segmen pada kata. Kaidah ini dapat dirumuskan seperti dibawah ini:

$\varnothing \rightarrow \mathrm{A} / \mathrm{B} \_\mathrm{C}$

3. Penyatuan Segmen (koalisi)

Penyatuan segmen adalah proses fonologis ketika dua suara bergabung menjadi suara tunggal yang memiliki sifat masing-masing dua suara asli. Seringkali suara yang dihasilkan memiliki tempat artikulasi salah satu suara sumber dan acara artikulasi yang lain. Dalam kaidah ini gugus konsonan maupun vokal diucapkan menjadi satu bunyi. Contoh rumus koalisi:

\section{[xy] $\rightarrow \mathrm{z} / \#$}

4. Asimilasi

Assimilation is the process of changing one phoneme into another phoneme as the result of putting morphemes together (Ramelan dalam Sutomo, 2012). Asimilasi adalah perubahan bunyi dari satu fonem menjadi fonem yang lain sebagai akibat dari peletakan morfem-morfem bersamaan. Dengan kata lain, asimilasi adalah dua bunyi yang tidak sama menjadi bunyi yang sama atau yang hampir sama. Hal ini terjadi karena bunyi-bunyi bahasa itu diucapkan secara berurutan sehingga berpotensi untuk saling mempengaruhi atau dipengaruhi sebagai akibat adanya lingkungan yang hampir sama.

Menurut Laver (1994:382-3) asimilasi adalah proses saling pengaruh antarbunyi mengakibatkan ciri-ciri bunyi yang dipengaruhi menjadi berubah untuk menyesuaikan dengan bunyi yang mempengaruhi, dan pengaruh itu dapat terjadi antarsegmen dalam suatu kata atau antar komponen dalam kata majemuk.

Asimilasi berdasarkan alur artikulasi dibagi menjadi asimilasi progresif dan regresif. Asimilasi progresif yaitu proses berpengaruhnya sebuah bunyi pada bunyi sesudahnya. Sedangkan asimilasi regresif yaitu proses berpengaruhnya sebuah bunyi pada bunyi sebelumnya.

Selain itu, ada pembagian jenis asimilasi berdasarkan pengaruh dari konsonan maupun vokal. Macammacam asimilasi ini, yaitu: (1) asimilasi Konsonan-Konsonan (K$\mathrm{K})$ : konsonan yang berasimilasi dengan konsonan; (2) asimilasi Konsonan-Vokal (K-V): konsonan yang berasimilasi dengan vokal; (3) asimilasi Vokal-Vokal (V-V): vokal yang berasimilasi dengan vokal; dan (4) asimilasi Vokal-Konsonan (V$\mathrm{K})$ : vokal yang berasimilasi konsonan.

Contoh rumus asimilasi:

[+sil] $\rightarrow$ [+nas] / _ [+nas]

Tulisan ini akan memberikan penjelasan tentang proses perubahan bunyi dalam tataran fonologis yang disertai dengan data yang diambil dari berbagai bahasa. Penjelasan tersebut diterangkan menggunakan kaidahkaidah fonologi generatif seperti yang sudah disampaikan diatas.

\section{DATA}

Untuk meneliti proses fonologis, diperlukan data fonologis yang memuat bentuk dasar dan bentuk turunan. Kedua bentuk ini digunakan untuk mendeteksi 
gejala-gejala perubahan fonologis yang muncul.

Dalam pengumpulan data penelitian, penulis mengambil data dari beberapa bahasa, antara lain, bahasa Indonesia, bahasa Jawa, bahasa Arab, dan bahasa Zoque. Dalam pengumpulan data yang berbahasa Jawa dan Indonesia, penulis memperolehnya dengan menggunakan metode reflektif-introspektif karena penulis adalah penutur asli bahasa Jawa dialek Kudus dan bahasa Indonesia. Reflektif-instropektif adalah metode pengambilan data linguistik dengan cara memanfaatkan intuisi kebahasaan peneliti yang meneliti bahasa yang dikuasainya (bahasa ibunya) untuk menyediakan data yang diperlukan bagi analisis yang sesuai dengan tujuan penelitiannya (Mahsun, 2007: 104). Untuk data selain dua bahasa tersebut, penulis memperolehnya dari buku.

Dalam menganalisis proses perubahan bunyi, penulis memakai beberapa tahap analisis. Data yang sudah terkumpul lalu diidentifikasi dan dikelompokkan berdasarkan jenis proses fonologisnya. Sebelum membuat hipotesis, penulis menentukan underlying form terlebih dahulu. Dari penentuan underlying form tersebut, penulis akan tahu gejala dan proses fonologis yang terjadi. Setelah itu, penulis merumuskan kaidah proses perubahan bunyi dengan menggunakan pendekatan fonologi generatif. Langkah selanjutnya adalah mendeskripsikan proses perubahan fonologis tersebut.

\section{PEMBAHASAN}

Bagian ini menjelaskan proses terjadinya perubahan bunyi yang dikaji menggunakan ancangan fonologi generatif. Proses fonologis tersebut antara lain: penambahan segmen, pelesapan segmen, penyatuan segmen, dan asimilasi.

\section{PENAMBAHAN SEGMEN}

Proses fonologis penambahan segmen dapat ditemukan pada bahasa Jawa dialek Kudus. Data dibawah ini merupakan unsur bahasa Jawa ragam ngoko yang terdapat pada dialek Jawa Kudus untuk menyatakan kepemilikan orang kedua.

\begin{tabular}{|c|c|c|}
\hline Nomina & & $\begin{array}{c}\text { Nomina + Kata } \\
\text { ganti kepemilikan } \\
\text { orang kedua } \\
\text { tunggal }\end{array}$ \\
\hline $\begin{array}{c}\text { sayu } \\
\text { 'uang saku' }\end{array}$ & $\rightarrow$ & $\begin{array}{c}\text { sayunəm } \\
\text { 'uang sakumu' }\end{array}$ \\
\hline $\begin{array}{l}\text { əmbว? } \\
\text { 'ibu' }\end{array}$ & $\rightarrow$ & $\begin{array}{l}\text { ibu?əm, } \\
\text { 'ibumu' }\end{array}$ \\
\hline $\begin{array}{l}\text { omah } \\
\text { 'rumah' }\end{array}$ & $\rightarrow$ & $\begin{array}{l}\text { smahəm } \\
\text { 'rumahmu' }\end{array}$ \\
\hline $\begin{array}{l}\text { rojs } \\
\text { 'raja' }\end{array}$ & $\rightarrow$ & $\begin{array}{l}\text { rojonəm } \\
\text { 'rajamu' }\end{array}$ \\
\hline $\begin{array}{l}\text { kəbo } \\
\text { 'kerbau' }\end{array}$ & $\rightarrow$ & $\begin{array}{l}\text { kəbonəm } \\
\text { 'kerbaumu' }\end{array}$ \\
\hline $\begin{array}{c}\text { bojo } \\
\text { 'suami/istri' }\end{array}$ & $\rightarrow$ & $\begin{array}{c}\text { bojonəm } \\
\text { 'suamimu/istrimu' }\end{array}$ \\
\hline $\begin{array}{c}\mathrm{p} \text { it } \\
\text { 'sepeda' }\end{array}$ & $\rightarrow$ & $\begin{array}{c}\text { pitəm } \\
\text { 'sepedamu' }\end{array}$ \\
\hline $\begin{array}{l}\text { səgo } \\
\text { 'nasi' }\end{array}$ & $\rightarrow$ & $\begin{array}{l}\text { səgənəm } \\
\text { 'nasimu' }\end{array}$ \\
\hline $\begin{array}{l}\text { saruy } \\
\text { 'sarung' }\end{array}$ & $\rightarrow$ & $\begin{array}{l}\text { saruyəm } \\
\text { 'sarungmu' }\end{array}$ \\
\hline $\begin{array}{l}\text { Buku } \\
\text { 'buku' }\end{array}$ & $\rightarrow$ & $\begin{array}{l}\text { bukunəm } \\
\text { 'bukumu' }\end{array}$ \\
\hline $\begin{array}{l}\text { klambi } \\
\text { 'baju' }\end{array}$ & $\rightarrow$ & $\begin{array}{l}\text { klambinəm } \\
\text { 'bajumu' }\end{array}$ \\
\hline
\end{tabular}

Dari data diatas dapat ditemukan bahwa /-əm/ merupakan underlying form karena imbuhan tersebut tidak dipengaruhi oleh lingkungan bunyi di sekitarnya. Sedangkan /-nəm/ tidak bisa dijadikan underlying form karena 
kemunculannya dipengaruhi oleh bunyi vokal yang mendahuluinya.

$$
\begin{aligned}
& \text { /sayu }+ \text {-əm / } \rightarrow \text { [sayunəm] } \\
& \text { /əmbว? +-əm / } \rightarrow \text { [ibuPəm] } \\
& \text { /omah }+- \text {-əm / } \rightarrow \text { [omahəm] } \\
& \text { / roj }+ \text {-əm / } \rightarrow \text { [rojənəm] } \\
& \text { /kəbo }+ \text {-əm / } \rightarrow \text { [kəbonəm] } \\
& \text { /səg }+-ə \mathrm{~m} / \quad \rightarrow \text { [səgənəm] } \\
& / \text { pit }+-\partial \mathrm{m} / \quad \rightarrow \text { [pitəm] } \\
& \text { /saruy }+- \text {-əm/ } \rightarrow \text { [saruyəm] } \\
& \text { /buku }+-ə \mathrm{~m} / \quad \rightarrow \text { [bukunəm] } \\
& \text { /klambi }+- \text {-əm/ } \rightarrow \text { [klambinəm] }
\end{aligned}
$$

Setelah menemukan underlying formnya dan mengujinya pada masingmasing data, data di atas menunjukkan adanya proses fonologis penambahan segmen pada stem yang diakhiri oleh vokal. $/ \mathrm{n} /$ disisipkan diantara stem dan sufiks. Proses penambahan segmen ini difungsikan untuk menghindari adanya gugus vokal atau bunyi vokal deret. Kaidah fonologis penambahan segmen ini adalah:

$$
(\varnothing) \rightarrow\left(\begin{array}{l}
+ \text { kon } \\
+ \text { nas } \\
- \text { kor } \\
- \text { ant }
\end{array}\right) /(+ \text { sil }) \quad(+ \text { sil })
$$

Keterangan:

Kaidah diatas menyatakan bahwa /n/ ditambahkan diantara dua bunyi vowel yang bersanding. Jadi, apabila kata dasar (stem) yang akan ditambahi akhiran /əm/ diakhiri oleh bunyi vowel [+sil], maka /n/ disisipkan di antara keduanya.

\section{PELESAPAN SEGMEN}

Dalam Bahasa Arab ditemukan proses fonologis pelesapan segmen, seperti contoh di bawah ini:

$\begin{array}{ccc}\begin{array}{c}\text { Verba masc. } \\ \text { orang ke-3 } \\ \text { tunggal }\end{array} & & \begin{array}{c}\text { Verba fem. orang } \\ \text { ke-3 tunggal }\end{array} \\ \text { Fíhim dia (lk) mengerti' } & \rightarrow & \text { 'dia (pr)mengerti' } \\ \text { šírib } & & \\ \text { 'dia (lk) minum' } & \rightarrow & \text { šírbat' } \\ \text { dia (pr) minum' }\end{array}$

$$
\begin{aligned}
& \text { hámal } \rightarrow \quad \text { hámalat } \\
& \text { 'dia (lk) 'dia (pr) } \\
& \text { membawa' membawa' } \\
& \begin{array}{l}
\text { kátab } \\
\text { 'dia (lk) menulis' }
\end{array} \quad \begin{array}{c}
\text { kátabat } \\
\text { 'dia (pr) menulis' }
\end{array}
\end{aligned}
$$

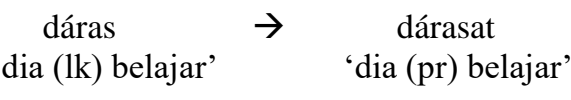

$$
\begin{aligned}
& \begin{array}{c}
\text { nízil } \\
\text { 'dia (lk) turun' }
\end{array}
\end{aligned}
$$

Akhiran /-at/ merupakan bentuk dasar (underlying form) dari morfem penanda orang ketiga tunggal feminin. Hal ini dapat dibuktikan bahwa penambahan akhiran /-at/ dapat berterima pada semua data yang ada.

$\begin{array}{lll}\text { /fíhim + -at/ } & \rightarrow & \text { [fíhmat] } \\ \text { /šírib + -at/ } & \rightarrow & \text { [Šírbat] } \\ \text { /hámal + -at/ } & \rightarrow & \text { [hámalat] } \\ \text { /kátab + -at/ } & \rightarrow & \text { [kátabat] } \\ \text { /dáras + -at/ } & \rightarrow & \text { [dárasat] } \\ \text { /nízil + -at/ } & \rightarrow & \text { [nízlat] }\end{array}$

Penambahan akhiran /-at/ tidak menimbulkan proses fonologis pada suku kata terakhir pada bentuk turunan. Akan tetapi, data diatas menunjukkan adanya proses morfologis pelesapan bunyi pada suku kata akhir pada stem yang menggunakan vowel /i/. Bunyi [i] pada suku kata terakhir stem dilesapkan ketika ada penambahan akhiran /-at/.

Kaidah Fonologis:

$$
\left(\begin{array}{l}
+ \text { ting } \\
- \text { ren }
\end{array}\right) \rightarrow \varnothing /-(+ \text { koo })\left(\begin{array}{l}
\text {-ting } \\
\text {-ren }
\end{array}\right)
$$

Keterangan:

Kaidah diatas menyatakan bahwa bunyi [i] dilesapkan ketika bertemu dengan konsonan yang diikuti oleh bunyi vokal [a].

\section{PENYATUAN SEGMEN/KOALISI}

Penambahan imbuhan /-an/ pada proses nominalisasi bahasa Jawa dari bentuk verba menjadi nomina menyebabkan terjadinya proses 
fonologis penyatuan segmen pada stem yang diakhiri oleh bunyi vokal.

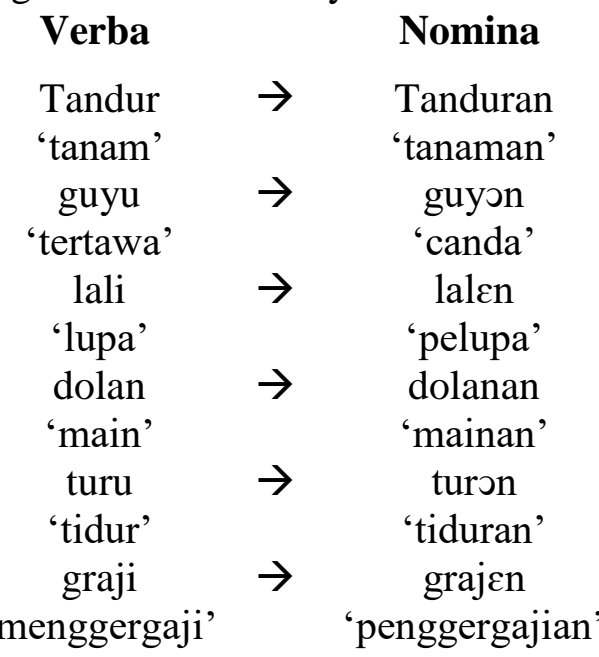

Dari data di atas diketahui bahwa akhiran /-an/ merupakan underlying form penanda nomina dalam bahasa Jawa. Penentuan underlying form ini dibuktikan dengan keberterimaan /-an/ pada stem yang diakhiri oleh konsonan. Pengujian dengan konsonan ini dilakukan karena bunyi pertama akhiran adalah bunyi vokal. Ketika akhiran /-an/ diuji dengan stem yang diakhiri oleh bunyi vokal, maka terjadi proses penyatuan segmen vokal.

$$
\begin{array}{lll}
\text { /tandur }+ \text {-an/ } & \rightarrow & \text { [tanduran] } \\
\text { /dolan }+- \text { an/ } & \rightarrow & \text { [dolanan] } \\
\text { /turu }+ \text {-an/ } & \rightarrow & \text { [turon] } \\
\text { /guyu }+ \text {-an/ } & \rightarrow & \text { guyon] } \\
\text { /lali }+- \text { an/ } & \rightarrow & {[\text { lalkn] }} \\
\text { /graji }+- \text { an/ } & \rightarrow & \text { grajen] }
\end{array}
$$

Dalam bahasa Jawa, keberadaan deret bunyi dapat menyebabkan proses penyatuan segmen. Data di atas menunjukkan bahwa bunyi deret [u] dan [a] dapat berubah menjadi satu bunyi yaitu [0] apabila bunyi deret tersebut diikuti oleh konsonan. Dan jika deret bunyi berupa [i] dan [a] maka berubah menjadi $[\varepsilon]$. Maka secara formal, pengkaidahan proses penyatuan bunyi tersebut dapat dirumuskan seperti di bawah ini:

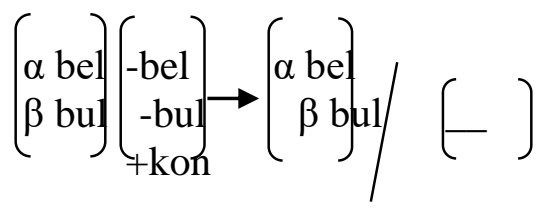

Keterangan:

Kaidah ini menyatakan bahwa bunyi [u] jika bersanding dengan bunyi [a] yang diikuti oleh konsonan maka akan berubah menjadi bunyi [0], dan bunyi [i] jika bersanding dengan bunyi [a] yang diikuti oleh konsonan maka akan berubah menjadi bunyi $[\varepsilon]$.

\section{ASIMILASI}

Pembubuhan afiks pada umumnya bisa memicu terjadinya perubahan bunyi. Salah satunya adalah asimilasi. Ada beberapa kaidah asimilasi diantaranya asimilasi regresif dan progresif. Berikut adalah penjelasan proses asimilasi dalam tinjauan fonologi generatif:

Dalam bahasa Arab terdapat proses penambahan prefiks /al-/ yang fungsikan sebagai penanda kata benda atau noun marker. Penambahan prefiks ini dapat menyebabkan proses asimilasi. Proses ini dikategorikan sebagai asimilasi regresif karena perubahan bunyi dipengaruhi oleh bunyi sesudahnya. Dalam hal ini prefiks /al-/ berasimilasi dengan bunyi setelahnya.

$\begin{array}{llll}\begin{array}{lll}\text { balad } \\ \text { mu?min }\end{array} & \rightarrow & \begin{array}{l}\text { al balad } \\ \text { al mu?min }\end{array} & \begin{array}{l}\text { 'negara' } \\ \text { 'orang } \\ \text { beriman' }\end{array} \\ \text { anbiya? } & \rightarrow & \text { al anbiya? } & \text { 'para nabi' } \\ \text { lail } & \rightarrow & \text { al lail } & \text { 'malam' } \\ \text { rosul } & \rightarrow & \text { ar rosul } & \text { 'utusan' } \\ \text { tarih } & \rightarrow & \text { at tarih } & \text { 'sejarah' } \\ \text { din } & \rightarrow & \text { ad dín } & \text { 'agama' } \\ \text { sá?ah } & \rightarrow & \text { as sá?ah } & \text { 'waktu' } \\ \text { ziyádah } & \rightarrow & \text { az ziyádah } & \text { 'tambahan' } \\ \text { nisa } & \rightarrow & \text { an nisa } & \text { 'perempuan }\end{array}$

*Data bahasa Arab ini dikutip dari Al Quran

Data di atas menunjukkan bahwa [al-] merupakan underlying form karena 
bunyi ini yang tidak dipengaruhi bunyi setelahnya. Ini dapat dibuktikan bahwa [al-] dapat berdistribusi pada bunyi sesudahnya yang berupa vowel.

$\begin{array}{lll}\text { /al- + balad/ } & \rightarrow & \text { [al balad] } \\ \text { /al- + mu?min/ } & \rightarrow & \text { [al mu?min] } \\ \text { /al- + anbiya?/ } & \rightarrow & \text { [al anbiya?] } \\ \text { /al- + lail/ } & \rightarrow & \text { [al lail] } \\ \text { /al- + rosul/ } & \rightarrow & \text { [ar rosul] } \\ \text { /al- + tilawah/ } & \rightarrow & \text { [at tiláwah] } \\ \text { /al- + din/ } & \rightarrow & \text { [ad dín] } \\ \text { /al- + sa?ah/ } & \rightarrow & \text { [as sá?ah] } \\ \text { /al- + ziyadah/ } & \rightarrow & \text { [az ziyádah] } \\ \text { /al- + nisa/ } & \rightarrow & \text { [an nisa] }\end{array}$

Dari penjabaran di atas dapat diketahui bahwa proses fonologisnya berupa asimilasi KK. Bunyi [1] dapat berubah menjadi beberapa bunyi konsonan lain disebabkan oleh pengaruh bunyi setelahnya. Secara sederhana perubahan tersebut dapat dilihat pada kaidah di bawah ini:

$$
[1] \rightarrow\left\{\begin{array}{c}
r \\
t \\
d \\
s \\
z \\
n
\end{array}\right\} \quad\left\{\begin{array}{l}
r \\
t \\
d \\
s \\
z \\
n
\end{array}\right\}
$$

Kaidah diatas dibaca: bunyi [1] dapat berubah menjadi bunyi $[\mathrm{r}]$ atau $[\mathrm{t}]$ atau [d] atau [s] atau [z] dan tau [n] apabila bertemu dengan bunyi-bunyi tersebut.

Kaidah Fonologis:

$$
\left(\begin{array}{l}
+ \text { ant } \\
+ \text { kor }
\end{array}\right) \rightarrow\left(\begin{array}{l}
\alpha \text { ant } \\
\beta \text { kor }
\end{array}\right) /\left(\begin{array}{l}
\alpha \text { ant } \\
\beta \text { kor }
\end{array}\right)
$$

Keterangan:

Kaidah ini menyatakan bahwa bunyi [1] dapat berubah menjadi bunyi [r] atau [t] atau [d] atau [s] atau [z] dan atau [n] apabila bertemu dengan bunyi $[\mathrm{r}]$ atau $[\mathrm{t}]$ atau $[\mathrm{d}]$ atau $[\mathrm{s}]$ atau $[\mathrm{z}]$ dan atau $[\mathrm{n}]$.
Contoh lain proses asimilasi terdapat dalam bahasa Zoque. Berbeda dengan contoh asimilasi sebelumnya yang bersifat total, contoh asimilasi di

\begin{tabular}{|c|c|c|}
\hline Nomina & & $\begin{array}{l}\text { Nomina + Kata ganti } \\
\text { kepemilikan } \\
\text { orang pertama } \\
\text { tunggal }\end{array}$ \\
\hline $\begin{array}{l}\text { plato } \\
\text { 'piring' }\end{array}$ & $\rightarrow$ & $\begin{array}{l}\text { mblato } \\
\text { 'piringku' }\end{array}$ \\
\hline $\begin{array}{l}\text { pama } \\
\text { 'pakaian' }\end{array}$ & $\rightarrow$ & $\begin{array}{c}\text { mbama } \\
\text { 'pakaianku' }\end{array}$ \\
\hline $\begin{array}{l}\text { kayu } \\
\text { 'kuda' }\end{array}$ & $\rightarrow$ & $\begin{array}{l}\text { jgayu } \\
\text { 'kudaku' }\end{array}$ \\
\hline $\begin{array}{l}\text { tuwi } \\
\text { 'anjing' }\end{array}$ & $\rightarrow$ & $\begin{array}{c}\text { nduwi } \\
\text { 'anjingku }\end{array}$ \\
\hline $\begin{array}{l}\text { tatah } \\
\text { 'ayah' }\end{array}$ & $\rightarrow$ & $\begin{array}{l}\text { ndatah } \\
\text { 'ayahku' }\end{array}$ \\
\hline $\begin{array}{l}\text { poco } \\
\text { 'adik' }\end{array}$ & $\rightarrow$ & $\begin{array}{l}\text { mboco } \\
\text { 'adikku' }\end{array}$ \\
\hline $\begin{array}{l}\text { kose } \\
\text { 'kakak } \\
\text { (pr)' }\end{array}$ & $\rightarrow$ & $\begin{array}{c}\text { ygose } \\
\text { 'kakakku (pr)' }\end{array}$ \\
\hline
\end{tabular}
bawah ini bersifat parsial atau sebagian.

*Data ini diambil dari buku The Descriptive Analysis of Words (A Nida 1949: 21)

Data tersebut menunjukkan bahwa bunyi /n/ diawal kata merupakan underlying form. Bunyi tersebut ini tidak dipengaruhi oleh bunyi di sekitarnya. Sedangkan $/ \mathrm{m} /$ dan $/ \mathrm{y} /$ dalam bentuk turunannya dipengaruhi oleh bunyi

\begin{tabular}{|c|c|c|}
\hline /n- + tuwi/ & $\rightarrow$ & [nduwi] \\
\hline /n- + kayu/ & $\rightarrow$ & [ngayu] \\
\hline /n- + kose/ & $\rightarrow$ & [ngose] \\
\hline /n- + plato/ & $\rightarrow$ & [mblato] \\
\hline$/ \mathrm{n}-+$ poco/ & $\rightarrow$ & [mboco] \\
\hline /n- + pama/ & $\rightarrow$ & [mbama] \\
\hline
\end{tabular}
tetangganya, yaitu: [b] dan [g].

Dari hasil analisis data di atas ditemukan bahwa ada dua kaidah fonologis. Kaidah fonologis pertama adalah proses perubahan ciri dari bunyi tidak bersuara menjadi bunyi bersuara. 
Semua stem yang diawali oleh bunyi tidak bersuara berubah menjadi bersuara, seperti: [p] menjadi [b]; [t] menjadi [d]; dan [k] menjadi [g] sebagai akibat adanya pengaruh nasal. Proses perubahan ciri ini juga bisa disebut sebagai asimilasi progresif karena perubahan bunyi dipengaruhi oleh bunyi yang sebelumnya.

Kaidah Fonologis 1:

$$
\text { [ -voice }] \rightarrow[+ \text { voice }] /[+ \text { nas }]
$$

Keterangan:

Kaidah ini menyatakan bahwa bunyi tak bersuara [-voice] menjadi bersuara [+voice] apabila jatuh setelah bunyi nasal $[\mathrm{n}],[\mathrm{m}]$, atau [n].

Kaidah kedua berupa proses fonologis asimilasi regresif parsial. Proses berubahnya /-n/ menjadi /-m/ atau /-n/ disebut asimilasi regresif karena perubahannya dipengaruhi oleh bunyi setelahnya. Dalam hal ini bunyi nasal [n] berasimilasi dengan bunyi berikutnya. Kaidah kedua dari data di atas secara sederhana dapat ditulis seperti berikut:

$$
[\mathrm{n}] \rightarrow\left\{\begin{array}{l}
\mathrm{y} \\
\mathrm{m}
\end{array}\right\} / \# \_\left\{\begin{array}{l}
\mathrm{k} \\
\mathrm{b}
\end{array}\right\}
$$

Kaidah di atas dibaca: bunyi [n] dapat berubah menjadi bunyi [ $\mathrm{y}]$ atau [m] apabila terletak di awal kata dan diikuti oleh /k/ atau /b/. Secara formal, kaidah ini dapat ditulis menjadi:

$$
\left(\begin{array}{c}
- \text { kor } \\
+ \text { ant }
\end{array}\right) \rightarrow\left(\begin{array}{l}
\alpha \text { kot } \\
\beta \text { ant }
\end{array}\right)=\left(\begin{array}{l}
\alpha \text { kor } \\
\beta \text { ant }
\end{array}\right)
$$

Keterangan:

Kaidah diatas menyatakan bahwa nasal $/ \mathrm{n} / \mathrm{di}$ posisi awal kata berubah menjadi /y/ apabila diikuti oleh bunyi $[\mathrm{k}]$; atau berubah menjadi $/ \mathrm{m} /$ apabila diikuti oleh bunyi [b].

\section{SIMPULAN}

Proses fonologis pada dasarnya adalah proses berubahnya bunyi kata atau frase karena adanya proses perubahan bunyi dari bentuk dasar ke bentuk turunan. Perubahan tersebut biasanya diakibatkan oleh afiksasi. Perubahan bunyi tersebut dapat berupa penambahan segmen, pelesapan segmen, penyatuan segmen, atau asimilasi. Dari penjelasan dan analisis diatas dapat disimpulkan bahwa peristiwa perubahan bunyi dan sebab-sebabnya dapat dijelaskan menggunakan ancangan fonologi generatif.

\section{DAFTAR PUSTAKA}

Dardjowidjojo, S. 2010. Psikolinguistik: Pengantar Pemahaman Bahasa Manusia, Edisi Kedua. Jakarta: Yayasan Obor Indonesia.

Eugene, A. N. 1949. The Descriptive Analysis of Words, second edition. Michigan: University of Michigan Press.

Odden, D. 2005. Introducing Phonology. Cambridge: Cambridge University Press.

Luqman, M. 2010. Fonologi Generatif. Makalah. Malang: Universitas Negeri Malang.

Mahsun. 2007. Metode Penelitian Bahasa: Tahapan Strategi, Metode, dan Tekniknya. Edisi Revisi. Jakarta: Rajawali Pers.

Ramelan. 1985. English Phonetics. Semarang: IKIP Semarang Press.

Sawirman. 2008. Suprasegmental sebagai Lahan Cultural Studies, ebook 135. Diunduh dari http://sawirman- 
e135.blogspot.com/2009/08/e-

135-sawirman-dansuprasegmental-2008.html.

Schane, S. A. 1992. Fonologi Generatif: Terjemahan Kentjanawati Gunawan. Jakarta: Summer Institute of LinguisticsIndonesia.
Sutomo, J. 2012. English phonological processes, a study of generative phonology. Jurnal Dinamika Bahasa dan Budaya Vol. 7 No.2 2012. Semarang: Unisbank.

Yusuf, S. 1998. Fonetik dan Fonologi. Jakarta: PT. Gramedia Pustaka Umum 